\title{
Characterization of several biological activities of porcine interferon gamma
}

\author{
Sophie LAVERNE, Laurence LAVENANT, B. CHARLEY \\ Institut National de la Recherche Agronomique, Station de Recherches de Virologie \\ et d'Immunologie, 78850 Thiverval-Grignon
}

E. coli-derived recombinant porcine interferon gamma ( $\mathrm{rPoIFN}-\tau$ ) exerts an antiviral activity against Coronavirus Transmissible Gastroenteritis infection of porcine kidney cells. In addition, rPoIFN $t$ is able to modulate immune responses in the pig. Thus, rPoIFN- $\tau$ at the dosis of $1 \mu \mathrm{g} / \mathrm{ml}$ increases spontaneous cytotoxic reactivities (or NK activity) of peripheral blood lymphocytes from 2-month old or less than 1-week old piglets. rPoIFN- $\tau$ is also active on blood monocyte cultures by increasing their Interleukine 1 secretory potential. These preliminary results illustrate the antiviral and immunomodulatory effects of porcine recombinant IFN- $\tau$.

\section{Sanitary state of pig herds from Brittany. 2. Lesions of the urogenital tract}

\author{
F. MADEC ${ }^{(1)}$, Françoise MARTINAT-BOTTE ${ }^{(2)}$, Marylène $\mathrm{KOBISCH}^{(1)}$
}

(1) Station de Pathologie Porcine, B.P. 9, 22440 Ploufragan

(2) Institut National de la Recherche Agronomique. Laboratoire de Physiologie de la Reproduction, Nouzilly, 37380 Monnaie

An abattoir study was conducted in Brittany (France) with the aim of evaluating urogenital tract lesion in culled sows. Samples were taken at random on the slaughter line in January 1986 and April 1987. A total of 225 sows were subjected to a macroscopic examination and 100 of them to histological and bacteriological investigations. A questionnaire was mailed to the farmers to get further information about the culled animals. The macroscopic examination showed a prevalence of metritis (12 p. 100), but many subclinical and chronic lesions were only detected by histological examination. The latter revealed a prevalence of $26 \mathrm{p} .100$ for metritis, of which 7 p. 100 were acute cases. Severe lesions of the bladder wall (cystitis) were recorded in $12 \mathrm{p} .10$ of the sows. Cystic follicles were detected in $6.2 \mathrm{p}$. 100 of the sows. Multiple big cysts were generally bilateral and associated with severe lesions of the urogenital tract and with anoestrus. Animals affected with cystitis and metritis were older than intact sows. Bacterial examinations revealed the presence of facultatively pathogens in metritis.

\section{Contribution to the analysis of the consequences of urinary troubles in an intensive sow rearing unit}

\author{
J. CASTAING, R. COUDURE
}

A.G.P.M., 122, boulevard Tourasse, 64000 Pau

A sudy was made in a herd of 180 Large White sows kept under intensive herd management conditions to determine the origin of farrowing and lactation disorders leading to important losses of piglets and to early culling of the sows. Sows were free from highly contagious diseases. More than one third exhibited a high urinary nitrite and/or protein or blood content indicating a severe urinary infection. This diagnosis was confirmed by the systematic autopsy of culled animals. 